\title{
Compartmentalization of extracellular cGMP determines absorptive or secretory responses in the rat jejunum
}

\author{
Xiao-Hong Jin, Helmy M. Siragy, Richard L. Guerrant, and Robert M. Carey \\ Department of Medicine, University of Virginia Health Sciences Center, Charlottesville, Virginia 22908, USA \\ Address correspondence and reprint requests to: Robert M. Carey, Box 395, University of Virginia Health Sciences Center, \\ Charlottesville, Virginia 22908, USA. Phone: (804) 924-5510; Fax: (804) 982-3626; E-mail: RMC4C@virginia.edu
}

Received for publication June 18, 1998, and accepted in revised form November 17, 1998.

\begin{abstract}
We examined potential mechanisms by which angiotensin subtype-2 $\left(\mathrm{AT}_{2}\right)$ receptor stimulation induces net fluid absorption and serosal guanosine cyclic $3^{\prime}, 5^{\prime}$-monophosphate (cGMP) formation in the rat jejunum. L-arginine (L-ARG) given intravenously or interstitially enhanced net fluid absorption and cGMP formation, which were completely blocked by the nitric oxide (NO) synthase inhibitor, $N$ nitro-L-arginine methylester (L-NAME), but not by the specific $\mathrm{AT}_{2}$ receptor antagonist, $\mathrm{PD}-123319$ (PD). Dietary sodium restriction also increased jejunal interstitial fluid cGMP and fluid absorption. Both could be blocked by PD or L-NAME, suggesting that the effects of sodium restriction occur via ANG II at the $\mathrm{AT}_{2}$ receptor. $\mathrm{L}-\mathrm{ARG}$-stimulated fluid absorption was blocked by the soluble guanylyl cyclase inhibitor $1-H-[1,2,4]$ oxadiazolo[4,2- $\alpha]$ quinoxalin-1-one (ODQ). Cyclic GMP-specific phosphodiesterase in the interstitial space decreased extracellular cGMP content and prevented the absorptive effects of L-ARG. Angiotensin II (ANG II) caused an increase in net $\mathrm{Na}^{+}$and $\mathrm{Cl}^{-}$ion absorption and ${ }^{22} \mathrm{Na}^{+}$unidirectional efflux (absorption) from the jejunal loop. In contrast, intraluminal heat-stable enterotoxin of Escherichia coli (STa) increased loop cGMP and fluid secretion that were not blocked by either L-NAME or ODQ. These findings suggest that ANG II acts at the serosal side via $\mathrm{AT}_{2}$ receptors to stimulate cGMP production via soluble guanylyl cyclase activation and absorption through the generation of NO, but that mucosal STa activation of particulate guanylyl cyclase causes secretion independently of NO, thus demonstrating the opposite effects of cGMP in the mucosal and serosal compartments of the jejunum.
\end{abstract}

J. Clin. Invest. 103:167-174 (1999).

\section{Introduction}

Angiotensin II (ANG II) regulates sodium and water transport across epithelial cells in the kidney and gastrointestinal tract (1-5). In the jejunum, low concentrations of ANG II stimulate sodium and water absorption while high concentrations inhibit absorption and/or stimulate secretion (3). We have recently demonstrated that ANG II stimulates absorption in the jejunum by an action at the $\mathrm{AT}_{2}$ receptor involving the generation of guanosine cyclic $3^{\prime}, 5^{\prime}$-monophosphate (cGMP) $(3,6,7)$.

In this study, we hypothesized that ANG II increases jejunal sodium and water absorption by increasing the synthesis of nitric oxide (NO) and stimulating soluble guanylyl cyclase. However, since cGMP is thought to mediate secretory, not absorptive, responses in the gastrointestinal tract when particulate guanylyl cyclase (GCC) is stimulated by the heat-stable enterotoxin of Escherichia coli (STa) or guanylin or uroguanylin $(8,9)$, we hypothesized that the sodium and water transport response, absorptive or secretory, is associated with a compartmentalized cGMP response via either soluble or particulate guanylyl cyclase. If so, STa would stimulate secretion by stimulating particulate guanylyl cyclase on the apical cell membrane of transporting epithelial cells. In contradistinction, nitric oxide would stimulate absorption via soluble guanylyl cyclase from the serosal side, and cGMP would be released predominantly across the basolateral membrane of epithelial cells into the interstitial space. We introduced both in situ loop and microdialysis techniques to test these hypotheses.

\section{Methods}

Animal preparation. Male Wistar rats weighing $200 \pm 15$ g were obtained from Harlan Bioproducts Inc. (Indianapolis, Indiana, USA). Rats were housed in a room with 12-h light-dark cycles and maintained on standard rat chow containing $0.28 \% \mathrm{NaCl}$ or low-sodium chow containing $0.08 \% \mathrm{NaCl}$ (BioServe Biotechnologies, Frenchtown, New Jersey, USA). Rats were fasted overnight before the study.

Operative procedure. Rats ( $n=8$ in each group) were anesthetized with pentobarbital sodium $70 \mathrm{mg} / \mathrm{kg}$ intraperitoneally (Veterinary Laboratories, Inc., Lenexa, Kansas). The trachea and left jugular vein were cannulated. A venous cannula (PE 50) was connected to a Harvard 975 infusion pump (Harvard Apparatus Co., South Natick, Massachusetts, USA) through which lactated Ringer's solution (vehicle) and drugs were infused. A ventral midline celiotomy also was performed and the jejunum was prepared in two different ways as described below.

Single-pass perfusion. These studies were performed according to previous publications $(10,11)$. An inlet cannula was placed just below the duodenal-jejunal flexure and the outlet cannula was $15 \mathrm{~cm}$ distal to the inlet cannula. The lumen just proximal and distal to the cannulated segment was tied off. To measure water transport, lactated Ringer's solution containing $\left[{ }^{14} \mathrm{C}\right]$ inulin $(15,000 \mathrm{dpm} / \mathrm{ml} ; 2.2 \mu \mathrm{Ci} / \mathrm{mg}$ specific activity; New England Nuclear, Boston, Massachusetts, USA) and phenol red (50 mg/liter, Sigma Chemical Company; St. Louis, Missouri, 
USA) was perfused. Single-pass continuous perfusion at a constant rate at $0.15 \mathrm{ml} / \mathrm{min}$ for $1 \mathrm{~h}$ was accomplished. For each rat, individual effluent samples were collected at 15, 30, 45, and $60 \mathrm{~min}$ after the initiation of perfusion. The first 15 -min sample was discarded. Samples at 30, 45, and 60 min were employed for analyzing fluid transport. The segment of gut then was emptied and reweighed to obtain the volume of the contents and the wet weight of the loop. An aliquot $(50 \mu \mathrm{l})$ of each sample was assayed for $\left[{ }^{14} \mathrm{C}\right]$ inulin by liquid scintillation spectrometry. The concentration change of phenol red was determined by spectrophotometer at wavelength $560 \mathrm{~nm}$. Water absorption was calculated by a standard formula $(10,11)$.

In situ loop technique. The methods and calculations were described in our previous reports $(3,7)$.

Measurement of $\mathrm{Na}^{ \pm}, \mathrm{Cl}^{-}$, or ${ }^{22} \mathrm{Na}^{ \pm}$unidirectional efflux. The same operative procedure was used as stated above $(3,7)$. The loop was filled with $3 \mathrm{ml}$ lactated Ringer's solution containing $\left[{ }^{14} \mathrm{C}\right]$ inulin (for $\mathrm{Na}^{+}$and $\mathrm{Cl}^{-}$net flux) or containing ${ }^{22} \mathrm{Na}^{+}(5 \mu \mathrm{Ci})$ and $3 \mathrm{mg}$ unlabeled inulin (for ${ }^{22} \mathrm{Na}^{+}$ion movement and loop volume determinations). A $0.15-\mathrm{ml}$ liquid sample was taken at time 0 , after which Ringer's solution was infused intravenously at $20 \mu \mathrm{l} / \mathrm{kg} / \mathrm{min}$ for $15 \mathrm{~min}$, followed by removal of a second $0.15-\mathrm{ml}$ sample. Subsequently, following infusion of ANG II, 0.7 $\mathrm{pmol} / \mathrm{kg} / \mathrm{min}$ for $15 \mathrm{~min}$, a third 0.15 -ml sample was removed. Samples $(385 \mu \mathrm{l})$ were used for $\mathrm{Na}^{+}$and $\mathrm{Cl}^{-}$determination by Nova Analyzer (Nova Biomedical, Waltham, Massachusetts,
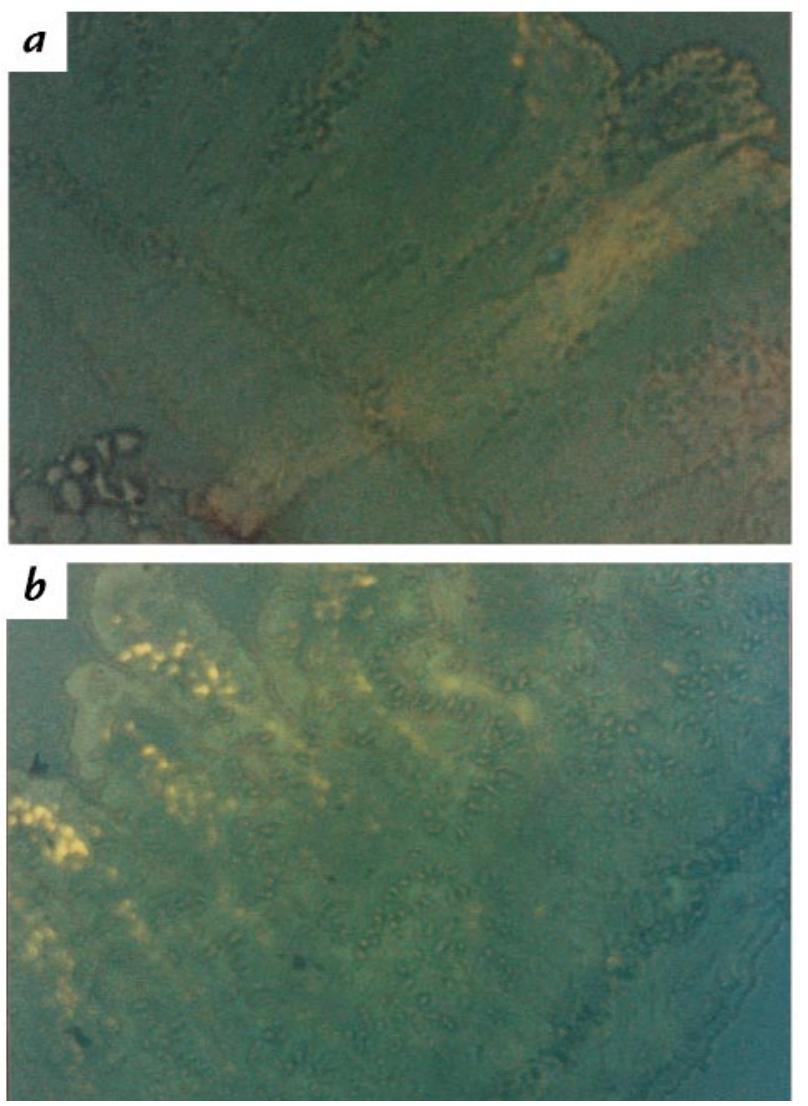

\section{Figure 1}

Frozen sections $(10 \mu \mathrm{m})$ of rat jejunum under fluorescence microscopy. $\times 200$. (a) Jejunal interstitial infusion with either lactated Ringer's solution as vehicle or $(\boldsymbol{b})$ fluo-angiotensin II. No fluorescence was observed in $a$. In $b$ the fluorescence signal was observed only in the submucosal layer of the jejunum. Each of four jejunal sections cut at 1,2, 4, and $6 \mathrm{~cm}$ from the infusion site in the jejunal submucosa demonstrated identical fluorescence signal as in $b$.
USA). Samples $(50 \mu \mathrm{l})$ were assayed for ${ }^{22} \mathrm{Na}^{+}$by gamma counting and for inulin by a standard method (12). We calculated $\mathrm{Na}^{+}$ and $\mathrm{Cl}^{-}$net absorption by the formula $V_{0} C_{0}-V_{X} C_{X}$ in which $V_{0}$ and $C_{0}$ are the volume of fluid and concentration of $\mathrm{Na}^{+}$or $\mathrm{Cl}^{-}$ at time 0 , and $V_{X}$ and $C_{X}$ are the volume and $\mathrm{Na}^{+}$or $\mathrm{Cl}^{-}$concentration after drug or vehicle administration for $15 \mathrm{~min}$. We calculated net $\mathrm{Cl}^{-}$and $\mathrm{Na}^{+}$flux by the formula: $V_{T} C_{T}=V_{x} C_{x}$, in which $T=$ test solution, $x=$ time $(0,15,30 \mathrm{~min}), V=$ volume of loop fluid, and $C=$ concentration of inulin. To calculate volume at time 0,15 , and $30 \mathrm{~min}$, the following formula was used: $3 \times$ $[\text { Inulin }]_{T}=V_{0} \times[\text { Inulin }]_{0}$. Then $\left(V_{0}-0.15\right) \times[\text { Inulin }]_{0}=V_{15} \times$ [Inulin $]_{15} .\left(V_{0}-0.15\right) \times[\text { Inulin }]_{0}=V_{30} \times[\text { Inulin }]_{30} . \mathrm{Net} \mathrm{Na}^{+}$or $\mathrm{Cl}^{-}$ flux was calculated using the measured $\mathrm{Na}^{+}$or $\mathrm{Cl}^{-}$with the calculated volumes from above as follows: $\mathrm{Net}^{+} \mathrm{Na}^{+}$flux from time 0 to $15 \mathrm{~min}$ as $\left(V_{0}-0.15\right) \times\left[\mathrm{Na}^{+}\right]_{0}-\left(V_{15}\right) \times\left[\mathrm{Na}^{+}\right]_{15}$ and from 15 to 30 min as $V_{15} \times\left[\mathrm{Na}^{+}\right]_{15}-\left(V_{30}\right) \times\left[\mathrm{Na}^{+}\right]_{30}$. Unidirectional ${ }^{22} \mathrm{Na}^{+}$ efflux in both control and ANG II-treated animals was calculated by comparing the total $\mathrm{dpm}$ of ${ }^{22} \mathrm{Na}^{+}$per min of the jejunal loop fluid at time 0,15 , and $30 \mathrm{~min}$. Changes in total dpm ${ }^{22} \mathrm{Na}^{+}$were calculated from the calculated volume (as above) multiplied by the measured $\mathrm{dpm}$ per $0.05 \mathrm{ml}$ of loop fluid at the beginning and end of each 15 -min study period.

In vivo jejunal microdialysis. For both collection of jejunal interstitial fluid and for introduction of substances (ANG II, cGMP, 8-Br-cGMP, and 1- $H$ - $[1,2,4]$ oxadiazolo[4,2- $\alpha]$ quinoxalin-1-one $[\mathrm{ODQ}]$ into the jejunal interstitium, we employed a microdialysis method previously described for the kidney and intestine $(7,13,14)$. The microdialysis membrane has a molecular weight cutoff of 10,000. Therefore, low molecular weight substances such as ANG II and cyclic nucleotides will freely pass across the membrane along their concentration gradients. Jejunal interstitial fluid can be collected for measurement of these substances or the substances can be infused directly into the interstitial space $(7,13,14)$. Injection of lissamine green B dye through the microdialysis fiber demonstrated localization only in the submucosal layer of the jejunal loop. Examination by fluorescence microscopy of fluorescein-labeled ANG II administered via the microdialysis fiber demonstrated that the dialysis tube was located in the submucosal area (Fig. 1) and that the infused substance was localized in the submucosa over the entire 15 -cm length of loop. It did not enter the muscularis mucosa or the lumen. For collection of interstitial fluid, the microdialysis technique has several advantages: First, jejunal interstitial fluid sampling provides the ability to monitor bioactive substances in vivo at most sites in any organ or tissue. Measurement of circulating hormones/autocoids may not reflect local changes within an organ or tissue. Second, repeated blood sampling in small animals may cause undesirable hemodynamic changes. Third, the concentration of hormones/drugs in the interstitial space is closer to target receptors than in the circulation. Fourth, the molecular weight cutoff of the microdialysis membrane can function as a barrier separating small and large molecules. This procedure can help exclude undesirable substances, such as degrading enzymes, and facilitate bioanalytical measurement in a small volume without complicated extraction procedures.

\section{Experimental protocols}

Effects of ANG II, L-arginine (L-ARG), PD-123319 (PD), N-nitro-Larginine methylester (L-NAME), and STa on jejunal fluid transport. To evaluate if increased water absorption stimulated by ANG II at the $\mathrm{AT}_{2}$ receptor is specifically related to NO production, we examined the effects of ANG II, L-ARG, and inhibitors on jejunal fluid absorption. The following drug groups were used for the second $15 \mathrm{~min}$ : (1a) ANG II $0.7 \mathrm{pmol} / \mathrm{kg} / \mathrm{min}$ (Peninsula Laboratories, Belmont, California, USA), individually or combined infusion with L-NAME; (2b) L-ARG (Sigma Chemical Co.) $40 / \mathrm{mg} / \mathrm{kg} / \mathrm{min}$ per rat intravenously or intraluminally (osmo- 


\section{Figure 2}

Effects of intravenous infusion of ANG II (0.7 $\mathrm{pmol} / \mathrm{kg} / \mathrm{min})$, or L-ARG $(40 \mathrm{mg} / \mathrm{kg} / \mathrm{min})$, or intraluminal infusion $\mathrm{STa}(0.01 \mu \mathrm{g} / \mathrm{ml})$ on $(\boldsymbol{a})$ water transport by single-pass perfusion or by $(\boldsymbol{b})$ an in situ jejunal loop preparation. Control data for the first $15 \mathrm{~min}$ are depicted by open bars, and data during drug infusion in the second $15 \mathrm{~min}$ are depicted by solid bars $(n=8)$. Each column represents the mean \pm 1 SE. ${ }^{*} P<0.01$; ***P<0.001 vs. control. There was no significant difference between the two techniques $(P=\mathrm{NS})$. ANG II, angiotensin II; L-ARG, L-arginine; STa, heat-stable enterotoxin of $E$. coli.

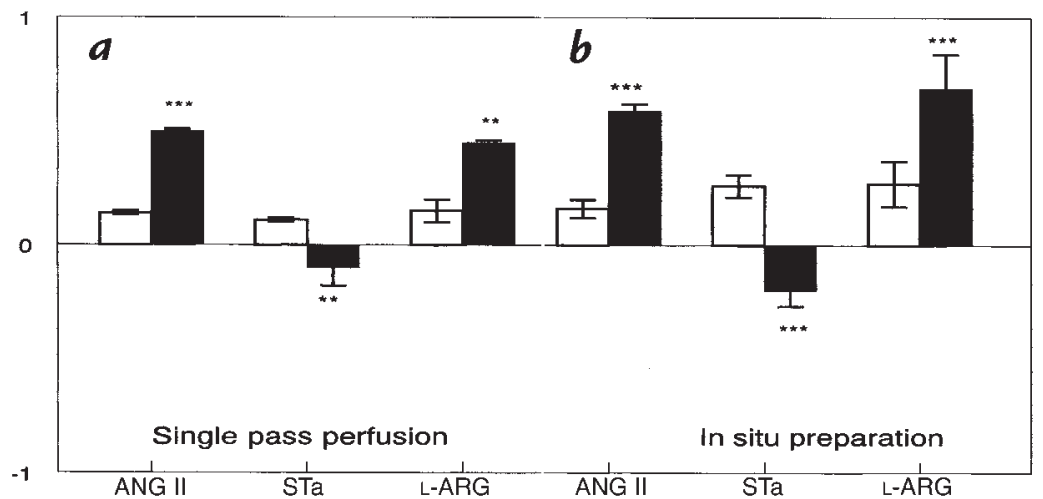

lality $2012 \pm 34 \mathrm{mOsm} / \mathrm{l}$ ), alone or combined with L-NAME (100 ng/kg/min, osmolality 267 mOsm/l; Sigma Chemical Co.) or with PD 123319 (PD; $25 \mu \mathrm{l} / \mathrm{kg} / \mathrm{min}$; Warner Lambert Co., Parke-Davis, Ann Arbor, Michigan, USA) (15). For experiments with the $\alpha_{1}$-adrenergic receptor antagonist, $200 \mathrm{mg}$ prazosin (Pfizer Pharmaceuticals, New York, New York, USA) was administered intravenously immediately before repeating LARG intravenous infusion. Intraluminal STa $0.1 \mu \mathrm{g} / 250 \mathrm{~g}$ rat alone or with L-NAME or ODQ, was infused to measure water transport. To assure that the effects of L-ARG intravenously on jejunal absorption were not related to osmotic effects, we administered an equiosmotic quantity of mannitol as a substitute for L-ARG in an identical protocol. Mannitol intravenously had no effect on absorption.

Effects of sodium depletion, L-NAME, and PD on jejunal interstitial fluid cGMP and jejunal fluid transport. In this study, we evaluated the relationship between physiological activation of the angiotensin subtype-2 $\left(\mathrm{AT}_{2}\right)$ receptor and NO production. Rats $(n=10$ in each group) were placed in metabolic cages. Daily 24 -h urine samples were collected for measurement of urinary sodium excretion (per $24 \mathrm{~h} \mathrm{U}_{\mathrm{Na}} \mathrm{V}$ ), and jejunal interstitial fluid (JIF) samples were obtained for cGMP determination. On day 0 rats consumed a normal sodium diet. Subsequently, the rats were placed on a low-sodium diet $(0.08 \%$ sodium $)$ for 7 days. On day 7 , rats were studied to determine fluid transport and jejunal interstitial fluid cGMP in response to $\mathrm{PD}$ and L-NAME by intravenous infusion.

Effects of L-ARG, ANG II, CGP-42112A (CGP), and STa on jejunal $c G M P$. This study was conducted to differentiate cGMP formation induced by stimulating the $\mathrm{AT}_{2}$ receptor from that due to $\mathrm{STa}$ administration. Drug groups were as follows: L-ARG 40 $\mathrm{mg} / \mathrm{kg} / \mathrm{min}$, ANG II $0.7 \mathrm{pmol} / \mathrm{kg} / \mathrm{min}$, and CGP $0.1 \mu \mathrm{g} / \mathrm{kg} / \mathrm{min}$ (CGP, a selective $\mathrm{AT}_{2}$ receptor agonist; Ciba-Geigy, Basel, Switzerland) (15) individually by intravenous infusion or combined with L-NAME intravenously. STa was administered intraluminally with or without an intravenous infusion of L-NAME.
Effects of cGMP, or 8-Br-cGMP (serosal or mucosal), or LARG and/or soluble guanylyl cyclase inhibitor on jejunal fluid absorption. This set of experiments was performed to identify compartmental responses to cGMP and to determine whether cGMP might serve as an extracellular mediator, since 8-BrcGMP, but not cGMP, administered extracellularly traverses the cell membrane and enters the intracellular space. We employed the specific inhibitor of soluble guanylyl cyclase, ODQ $(16,17)$. Drug groups include cGMP or 8-Br-cGMP (each at $0.6 \mu \mathrm{mol}$ ) administered interstitially or intraluminally. LARG $40 \mathrm{mg} / \mathrm{kg} / \mathrm{min}$ intravenous infusion or combined with ODQ $(100 \mu \mathrm{M})$ was infused interstitially via a microdialysis catheter. To assure that GMP infused interstitially did not produce systemic effects, we measured plasma cGMP concentration before and after interstitial cGMP infusion. Plasma cGMP was $3.76 \pm 0.36 \mathrm{pmol} / \mathrm{ml}$ before and $4.56 \pm 0.36 \mathrm{pmol} / \mathrm{ml}(P=$ NS) after interstitial cGMP administration.

Effects of jejunal interstitial fluid administration of cGMP phosphodiesterase on CGMP and fluid absorption. This study was designed to clarify the role of extracellular cGMP in the regulation of fluid absorption. We infused type VI cGMP-specific phosphodiesterase $(\mathrm{PDE})(\mathrm{mol} \mathrm{wt}=216,000$; Calbiochem-Novabiochem Corp., San Diego, California, USA) (18) interstitially using an open-bore (PE 10) catheter at infusion rates from 0.01 to $0.12 \mu \mathrm{g} / \mathrm{kg} / \mathrm{min}$ for 30 min. We simultaneously quantified jejunal interstitial fluid cGMP and cAMP levels using microdialysis. We selected an infusion rate of PDE, which significantly reduced jejunal interstitial fluid cGMP and did not influence cAMP for subsequent studies. While infusing cGMP-specific PDE, we quantified the jejunal interstitial fluid cGMP and fluid absorption responses to intravenous infusion of L-ARG $40 \mathrm{mg} / \mathrm{kg} / \mathrm{min}$.

Analytical methods. Urinary sodium excretion was measured by a Nova Analyzer (Nova Biomedical). Jejunal interstitial and loop fluid cGMP levels were measured by enzyme immunoassay kit (Cayman Chemical, Ann Arbor, Michigan, USA). The a

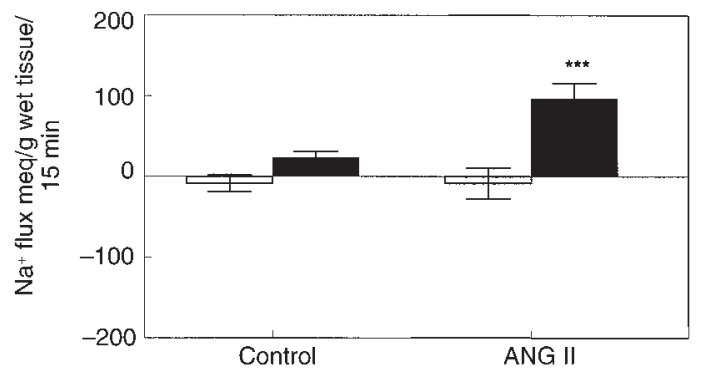

$b$

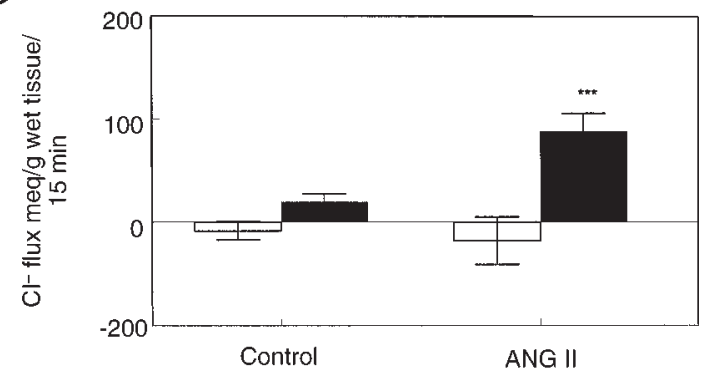

Figure 3

Effect of ANG II $(0.7 \mathrm{pmol} / \mathrm{kg} / \mathrm{min})$ on (a) net jejunal sodium absorption and $(\boldsymbol{b})$ chloride absorption in the rat. Histograms represent mean $\pm 1 \mathrm{SE}$ of jejunal sodium and chloride measured over two consecutive 15 -min periods in separate animals $(n=6)$. Open bars represent the first 15 min controls, and solid bars denote sodium and chloride absorption in the second 15 min during vehicle or ANG II infusion. ${ }^{* *} P<0.001$ vs. the control group. 


\section{Figure 4}

Effect of ANG II ( $0.7 \mathrm{pmol} / \mathrm{kg} / \mathrm{min})$ on unidirectional ${ }^{22} \mathrm{Na}^{+}$movement in jejunal loops $(n=8)$. Points represent mean $\pm 1 \mathrm{SE}$ of natural log of total ${ }^{22} \mathrm{Na}^{+}$content in the loop at time 0,15 , and 30 min measured over two 15 min periods. The solid line denotes values when vehicle was infused, and the dashed line denotes values when ANG II was infused intravenously after the 15 -min control period. ANG II caused a significant reduction of ${ }^{22} \mathrm{Na}^{+}$in the loop $(P<0.05)$.

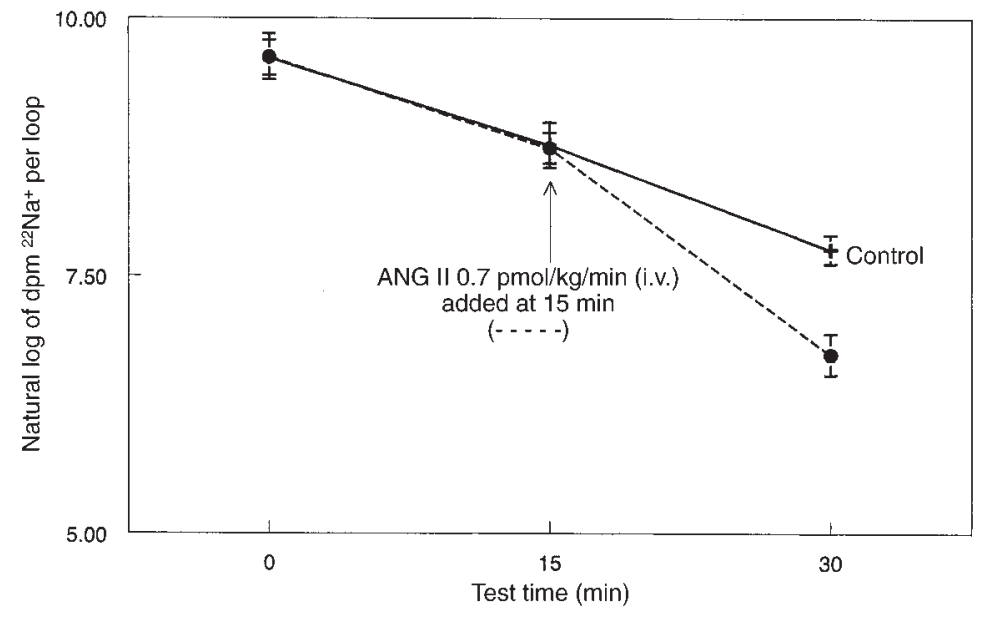

sensitivity and specificity of this method for cGMP were 0.11 $\mathrm{pmol} / \mathrm{ml}$ and $100 \%$, respectively. The inter- and intra-assay coefficients of variation were less than $10 \%$. Cross-reactivity of the cGMP assays with other cyclic nucleotides was less than $0.01 \%$.

Statistics. Results are presented as mean \pm 1 SE. Data were analyzed by Student's paired or unpaired $t$ tests as appropriate. ANOVA was used for multiple comparisons. $P<0.05$ were considered statistically significant.

\section{Results}

Jejunal fluid transport by single-pass perfusion and in situ loop techniques. As shown in Fig. 2, there was no significant difference in the results between the two techniques. In each case, ANG II and L-ARG both caused a significant increase in absorption while STa stimulated a secretory response. Since there was no difference between these techniques, we selected the in situ jejunal loop technique for all succeeding experiments because it is easier technically and requires less isotope than single-pass perfusion.

Effects of ANG II on $\mathrm{Na}^{+}$and $\mathrm{Cl}^{-}$net ion transport and ${ }^{22} \mathrm{Na}^{ \pm}$ unidirectional efflux. We found that $\mathrm{Na}^{+}$and $\mathrm{Cl}^{-}$concen- trations in the jejunal loops were not affected by ANG II. Thus, net $\mathrm{Na}^{+}$and $\mathrm{Cl}^{-}$transport paralleled net water transport. ANG II increased the net absorption of $\mathrm{Na}^{+}$ and $\mathrm{Cl}^{-}$from the loops (Fig. 3, $a$ and $b$ ). Furthermore, ANG II increased the unidirectional efflux of ${ }^{22} \mathrm{Na}^{+}$from the loops (Fig. 4), whether compared with the same loop prior to addition of ANG II or compared with loops in control animals followed throughout the study periods ( $P<0.05$ for both comparisons).

Effects of ANG II, L-ARG, PD, L-NAME, and STa on jejunal fluid absorption. As seen in Fig. 5, ANG II caused a highly infused intravenously or interstitially. The increase in absorption in response to ANG II was blocked completely with L-NAME. Intravenous administration of L-ARG also caused a highly significant increase in absorption, which was blocked completely in the presence of L-NAME. Intraluminal administration of the same dose of L-ARG caused a highly significant secretory response that was not affected by L-NAME. Because we suspected that the secretory response to L-ARG intraluminally was due to an osmotic significant increase in absorption whether the peptide was

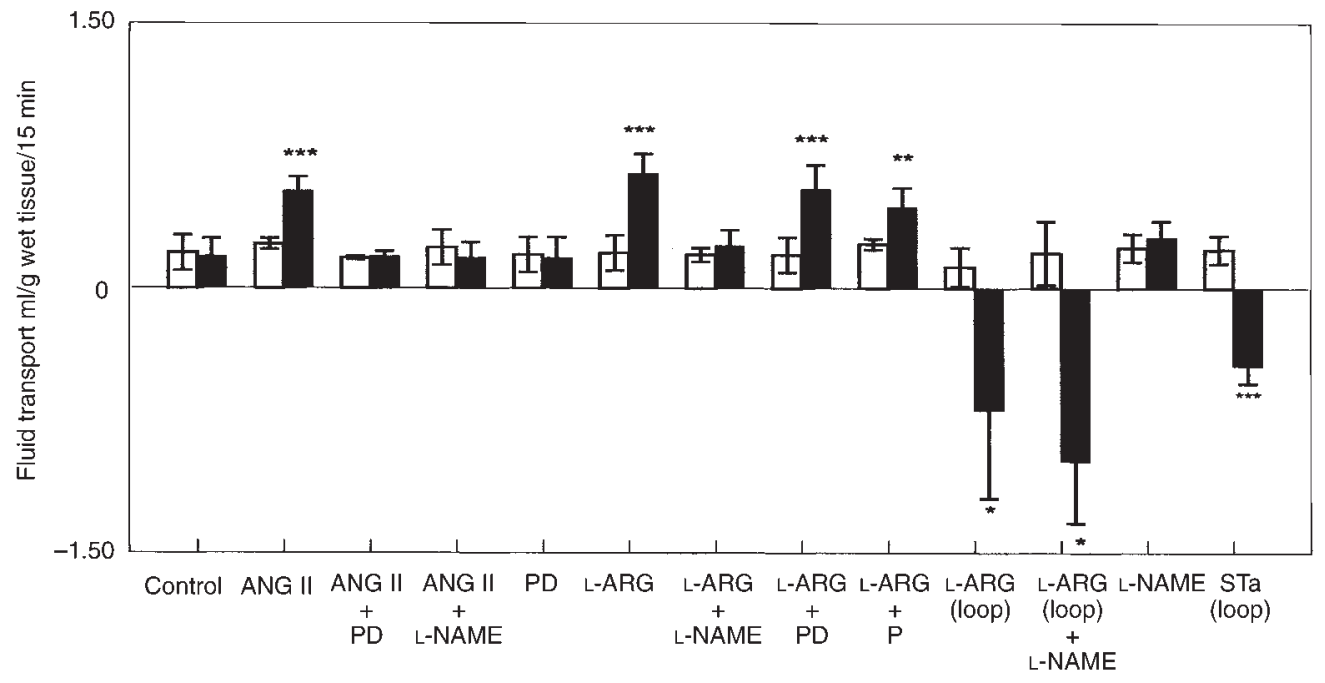

\section{Figure 5}

Effects of ANG II $0.7 \mathrm{pmol} / \mathrm{kg} / \mathrm{min}$ intravenously or L-ARG $40 \mathrm{mg} / \mathrm{kg} / \mathrm{min}$ intravenously or intraluminally (loop) on jejunal fluid transport in the presence or absence of L-NAME $100 \mathrm{ng} / \mathrm{kg} / \mathrm{min}$ or PD $25 \mu \mathrm{g} / \mathrm{kg} / \mathrm{min}$ or prazosin $(P) 200 \mathrm{mg}$ intravenously. Intraluminal STa caused water secretion, which was not affected by L-NAME or ODQ (data not shown). Each group $(n=8)$ has its own control for the first 15-min (open bars) and the second 15$\min$ (solid bars) infusion of vehicle or pharmacologic agents. Each column represents mean $\pm 1 \mathrm{SE} .{ }^{*} P<0.05 ;{ }^{*} P<0.01 ;{ }^{* * *} P<0.001$ vs. control values. L-NAME, N-nitro-L-arginine methylester; ODQ, 1-H-[1,2,4]oxadiazolo[4,2- $\alpha]$ quinoxalin-1-one. 


\section{Figure 6}

Twenty-four-hour urinary sodium excretion $\left(\mathrm{U}_{\mathrm{Na}} \mathrm{V}\right)$ (dashed lines) and jejunal interstitial fluid cGMP levels (solid lines) in conscious rats $(n=8)$ on normal sodium intake $(\mathrm{NNa})$ and on each day of a 7-day period of dietary sodium restriction $(L N a)$. Data represent mean $\pm 1 \mathrm{SE} .{ }^{*} P<0.05 ;{ }^{*} P<$ $0.01 ;{ }^{*}{ }^{*} P<0.001$ vs day 0 . JIF, jejunal interstitial fluid.

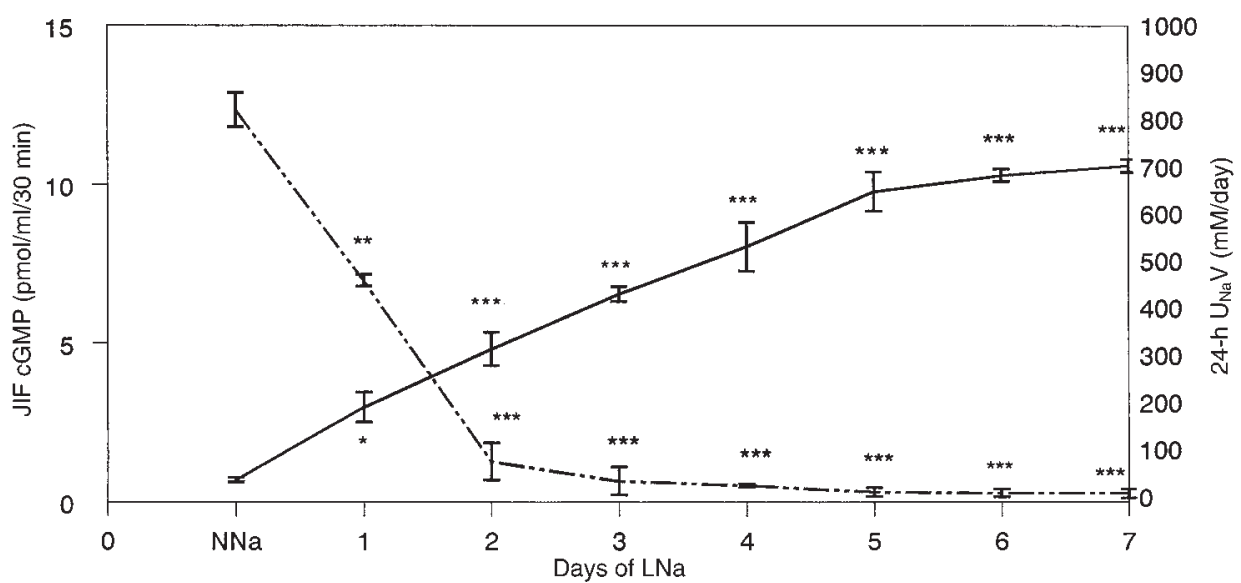

effect, we infused an equal osmotic quantity of mannitol intraluminally and reproduced a secretory response similar in magnitude to that with L-ARG (data not shown). We also demonstrated no effect on fluid transport with the same quantity of mannitol intravenously (data not shown). L-NAME alone, which was not hyperosmolar, had no effect on fluid absorption. The combination of PD and L-NAME had no additive effect, but prevented the increase in absorption engendered by ANG II (data not shown). The increase in water absorption in response to L-ARG was not influenced by either PD or the $\alpha$-adrenergic antagonist, prazosin, which we have shown blocks ANG II-induced absorption (7). Instillation of STa into the loop caused a highly significant secretory response that was not affected by intravenous administration of L-NAME or ODQ intraluminally or interstitially (data not shown).

Responses of jejunal water absorption and interstitial fluid cGMP to dietary sodium restriction, $P D$, and L-NAME. Dietary sodium restriction induced a highly significant decrease in 24-hour urinary sodium excretion (Fig. 6). Jejunal interstitial fluid cGMP was $0.31 \pm 0.14 \mathrm{pmol} / \mathrm{ml} / 30 \mathrm{~min}$ during normal sodium intake and increased in a highly significant and stepwise fashion to $12.5 \pm 0.53 \mathrm{pmol} / \mathrm{ml} / 30 \mathrm{~min}(P<$ 0.0001 ) by day 7 of sodium restriction (Fig. 6). On the seventh day of sodium depletion, jejunal fluid absorption was increased from normal sodium diet at $0.18 \pm 0.02$ in rats on normal sodium intake to $0.51 \pm 0.08 \mathrm{ml} / \mathrm{g}$ wet tissue $/ 15$ $\min (P<0.01)$ for the second 15 minutes. As shown in Fig. 7 , the increases in fluid absorption (Fig. $7 a$ ) and in jejunal interstitial fluid cGMP (Fig. 7b) were inhibited to control values prior to sodium restriction by either PD or L-NAME. Effects of L-ARG, ANG II, CGP, L-NAME, and STa on jejunal interstitial and intraluminal cGMP. Intravenous L-ARG, ANG II, and CGP increased jejunal interstitial fluid cGMP $(P<0.0001)$, and these responses all could be blocked completely with L-NAME (Fig. 8a). However, LARG or STa administered intraluminally had no effect on jejunal interstitial fluid cGMP. L-NAME alone did not alter jejunal interstitial fluid cGMP (Fig. 8a). Intravenous ANG II caused a small but highly significant increase in loop cGMP, which was blocked by L-NAME or PD, and intravenous L-ARG also caused a highly significant increase in loop cGMP that was blocked with L-NAME. Intraluminal L-ARG had no effects on loop cGMP. Intraluminal STa caused a highly significant increase in loop cGMP that was not inhibited with intravenous L-NAME.

Effects of $c G M P, 8-B r c G M P$, or $L-A R G$, alone or combined with soluble guanylyl cyclase inbibitor $O D Q$ on jejunal fluid transport. L-ARG administered intravenously and cGMP interstitially increased jejunal fluid absorption (Fig. 9). This effect was mimicked by 8-Br-cGMP. Both cyclic nucleotides infused intraluminally inhibited fluid absorption. Interstitial ODQ had no effect on fluid transport by itself, but blocked the increase in absorption engendered by intravenous L-ARG or interstitial cGMP. ODQ interstitially or intraluminally did not affect the secretory response to cGMP intraluminally.

Effects of cGMP-specific PDE on cGMP and L-ARG-induced

\section{$\boldsymbol{b}$}

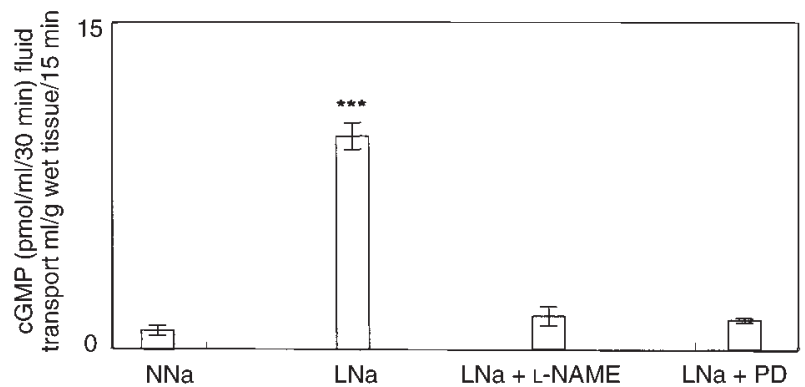

Figure 7

Effects of L-NAME and PD on jejunal fluid absorption and jejunal interstitial fluid cGMP levels in rats ( $n=8$ per group) on normal sodium intake $(\mathrm{NNa})$ and after 7 days of dietary sodium restriction $(\mathrm{LNa})$. (a) Shown is the fluid transport, in which each group has its own control (open bars). Solid bars represent data from the second 15 -min infusion of vehicle or pharmacologic agents. (b) Here jejunal interstitial fluid cGMP production can be seen. Each column represents mean $\pm 1 \mathrm{SE} .{ }^{*} P<0.01 ;{ }^{* *} P<0.001$ vs. NNa. 

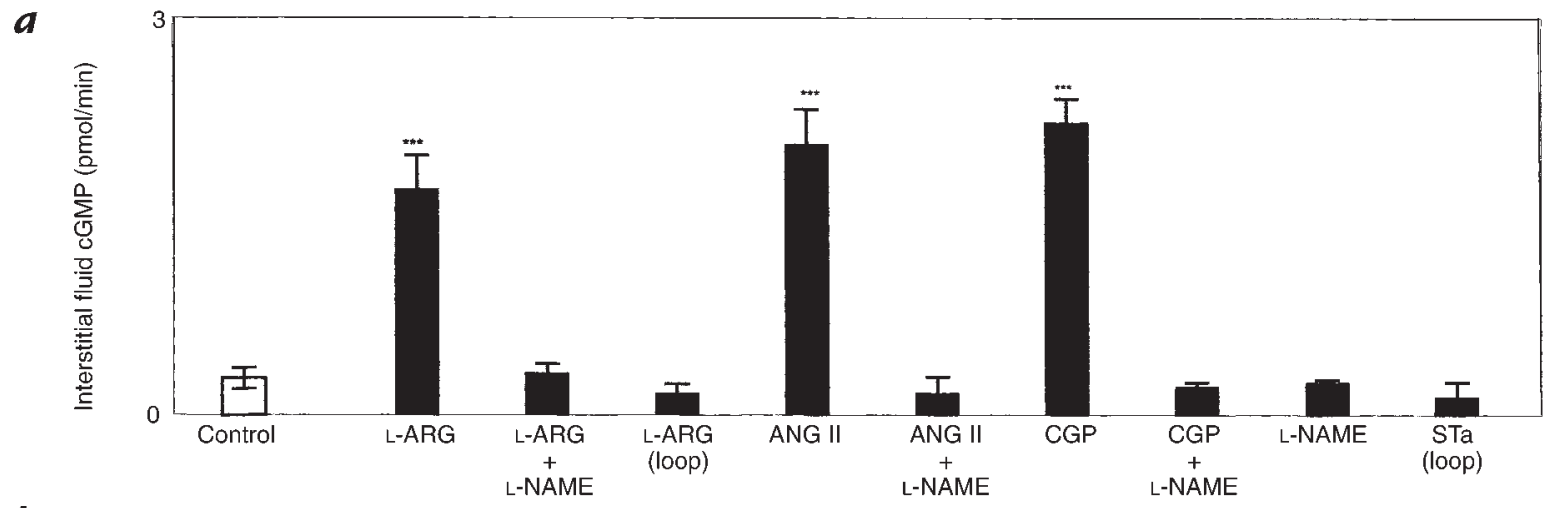

$b$

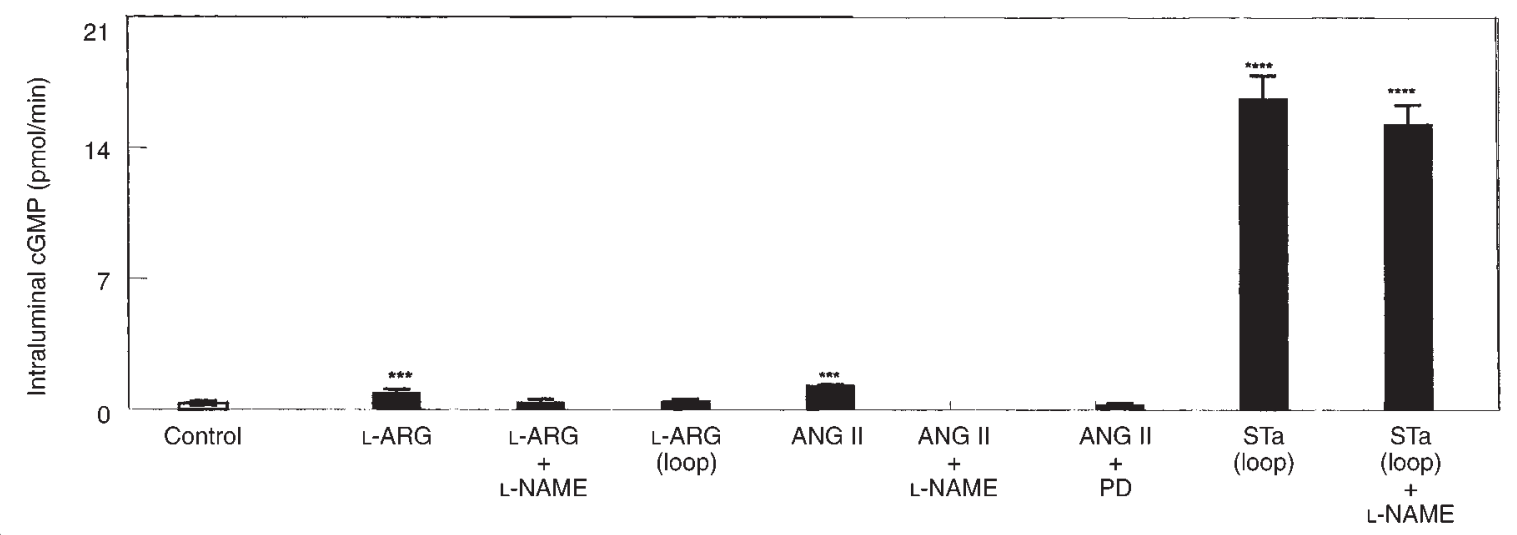

Figure 8

(a) Jejunal interstitial fluid cGMP responses to L-ARG $40 \mathrm{mg} / \mathrm{kg} / \mathrm{min}$ intravenously or intraluminally (loop), ANG II $0.7 \mathrm{pmol} / \mathrm{kg} / \mathrm{min}, \mathrm{CGP} 0.1$ $\mu \mathrm{g} / \mathrm{kg} / \mathrm{min}$ intravenously, or STa infused intraluminally (loop) in the presence or absence of L-NAME. (b) Intraluminal cGMP responses to L-ARG intravenously or intraluminally (loop), ANG II intravenously, or STa intraluminally (loop) in the presence or absence of L-NAME or PD. Open bars represent controls and solid bars represent drug infusion. Each column represents the mean $\pm 1 \mathrm{SE}$. ${ }^{* * *} P<0.001 ;{ }^{* * *} P<0.0001 \mathrm{vs}$. control; $n=8$ for each group.

fluid absorption and cGMP. Figure $10 a$ demonstrates the dose-response relationship of PDE administered interstitially on jejunal interstitial fluid cGMP and adenosine $3^{\prime}, 5^{\prime}$ cycllic monophosphate (cAMP) levels. An infusion rate of $0.12 \mu \mathrm{g} / \mathrm{kg} / \mathrm{min}$ significantly reduced jejunal interstitial fluid cGMP without affecting cAMP. Figure $10 b$ shows that interstitial PDE at $0.12 \mu \mathrm{g} / \mathrm{kg} / \mathrm{min}$ completely blocked an increase in jejunal interstitial fluid cGMP due to intravenous L-ARG. Figure $10 c$ shows that interstitial PDE also blocked the increase in fluid absorption engendered by intravenous L-ARG $40 \mathrm{mg} / \mathrm{kg} / \mathrm{min}$.

\section{Discussion}

This study demonstrates for the first time, to our knowledge, that ANG II increases jejunal fluid absorp- tion via nitric oxide production. We have previously shown that ANG II increases jejunal absorption via the $\mathrm{AT}_{2}$ receptor resulting in release of cGMP into the jejunal loop (7). In this study, we confirmed that $\mathrm{AT}_{2}$ receptor-mediated fluid and sodium absorption is blocked by inhibition of nitric oxide synthase. Since L-NAME alone (in the absence of ANG II) did not alter jejunal fluid absorption and $\mathrm{AT}_{2}$ receptor blockade did not prevent the increase in absorption with L-ARG, we conclude that ANG II increases absorption by $\mathrm{AT}_{2}$ receptor-mediated nitric oxide production.

Our results are consistent with the recent reports of Schirgi-Degen and Beubler $(19,20)$ that nitric oxide enhances fluid absorption in the rat intestine. In contradistinction to these findings regarding the intravenous

\section{Figure 9}

Jejunal fluid transport $(n=8$ in each group) responses to JIF or intraluminal (loop) administration of CGMP, or 8-BrcGMP, or L-ARG intravenously in the presence or absence of JIF or intraluminal (loop) ODQ infusion. ${ }^{*} P<0.01 ;{ }^{*} * P<$ 0.001 vs. control.

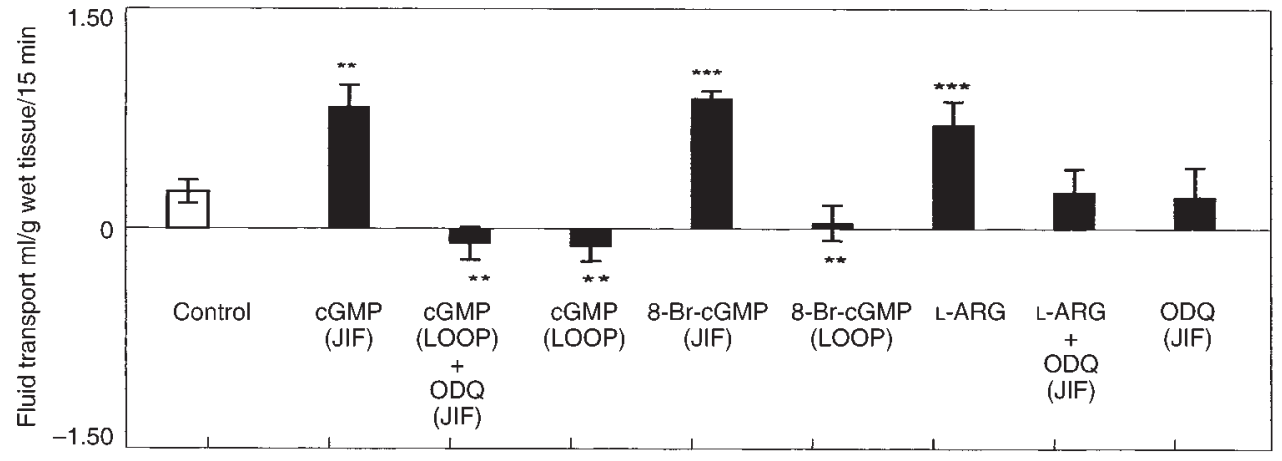




\section{Figure 10}

(a) Jejunal interstitial fluid cGMP (solid line) and cAMP (dashed line) responses to interstitial cGMPspecific PDE administration $(n=8)$. (b) Jejunal interstitial fluid cGMP responses to intravenous infusion of L-ARG with or without interstitial infusion of cGMP-specific PDE $0.12 \mu \mathrm{g} / \mathrm{kg} / \min (n=8)$. (c) Jejunal fluid transport responses to intravenous infusion of L-ARG in the presence or absence of concurrent interstitial PDE $(n=9)$ administration. ${ }^{*} P<0.05$; ${ }^{* *} P<0.001 ;{ }^{* * * *} P<0.0001$ vs. control. $P D E$, phosphodiesterase. a

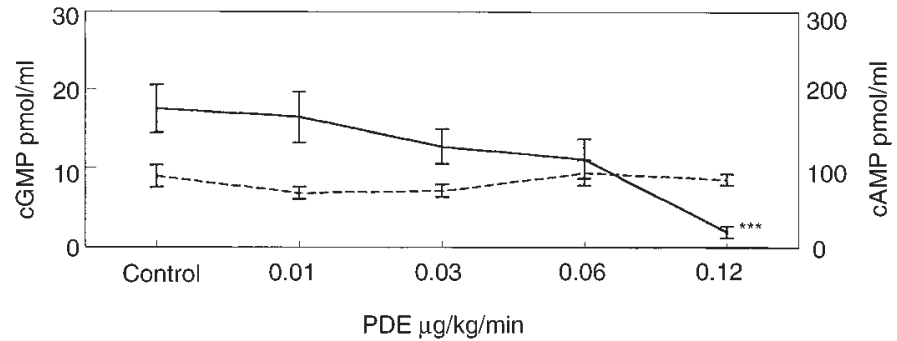

$\boldsymbol{b}$

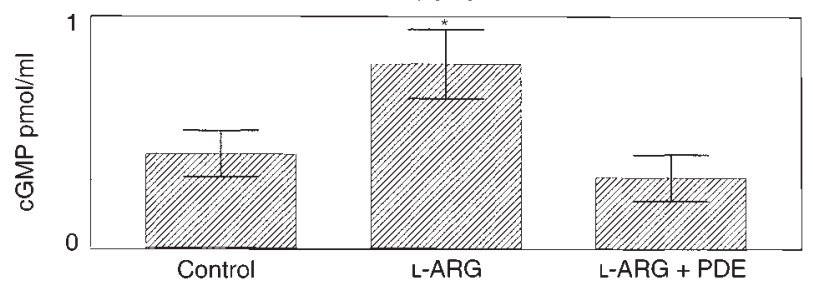

c

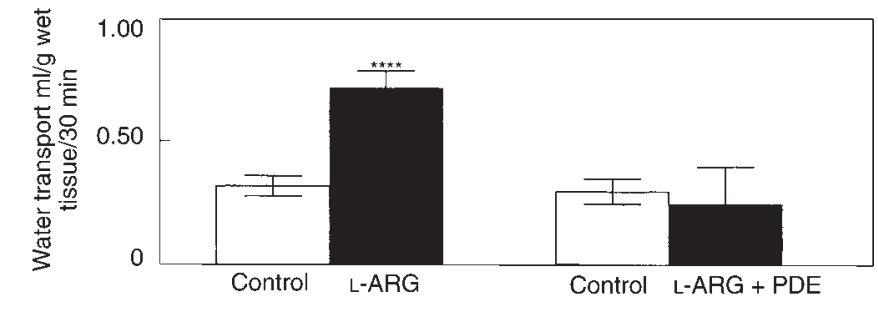

administration of L-ARG, we demonstrated that intraluminal L-ARG produced dose-dependent fluid secretion that was not influenced by L-NAME. The results are similar to those of Mourad et al. (21) in which intraluminal administration of L-ARG caused secretion in the rat jejunum. Beubler and Schirgi-Degen (22) also reported that addition of L-arginine to the oral rehydration solution used in the treatment of diarrheal illness in humans did not augment the antisecretory effect of the oral rehydration solution. Because we demonstrated a secretory response to an equiosmotic quantity of mannitol intraluminally, we interpret our results to mean that intraluminal L-ARG caused secretion most likely by an osmotic effect independent of nitric oxide production.

ANG II receptors have been reported to release nitric oxide in systemic arterial vessels and in the kidney $(23,24)$. ANG II was demonstrated to increase cGMP formation in rat aortic segments and in bovine aortic endothelial cells, effects that were not blocked by $\mathrm{AT}_{1}$ receptor blockade (losartan), but were blocked by nitric oxide synthase inhibitor L-NAME $(25,26)$. Recently, Gohlke et al. (27) demonstrated that ANG II stimulated aortic cGMP by a mechanism involving bradykinin and nitric oxide mediated by the $\mathrm{AT}_{2}$ receptor in stroke-prone spontaneously hypertensive rats. We have recently shown that ANG II stimulates renal interstitial fluid cGMP by an action at the $\mathrm{AT}_{2}$ receptor mediated by nitric oxide (28). Taken together with the results of this study, we conclude that $\mathrm{AT}_{2}$ receptor stimulation releases nitric oxide and cGMP in a variety of tissues, including the jejunum. The effects of ANG II on $\mathrm{AT}_{2}$ receptor activation and nitric oxide production, while most likely on epithelial cells, could also be located on nonepithelial cells such as enteric nerves, vascular smooth muscle, endothelial cells, or endocrine cells.

In this study, we demonstrated that, similar to what occurs in the kidney $(13,28)$, dietary sodium restric- tion increased jejunal fluid absorption and interstitial fluid cGMP in stepwise fashion, which were blocked approximately equally by PD and L-NAME. These results suggest that ANG II, via the $\mathrm{AT}_{2}$ receptor, increased nitric oxide production in response to a physiologic stimulus, sodium restriction.

The major finding of this study was that the cGMP responses had opposite effects, depending on whether particulate guanylyl cyclase was stimulated from the mucosal side or whether soluble guanylyl cyclase was stimulated via a NO synthase-dependent pathway on the serosal side. We were able to demonstrate that cGMP interstitially increases absorption without altering circulating cGMP concentrations. Although it is highly unlikely that interstitial administration of cGMP results in spillover to the systemic circulation, we cannot be completely sure that cGMP interstitially is devoid of systemic effects. It is generally accepted that STa, along with related peptides guanylin and uroguanylin, causes a secretory response by binding to an apical membrane receptor that contains the guanylyl cyclase catalytic domain within the cytoplasmic portion of the protein $(29,30)$. The binding of STa to this receptor enhances the production and intracellular accumulation of cGMP, which in the intestinal epithelium results in secretion of chloride and bicarbonate into the intestinal lumen. This pathophysiologic action of bacterial STa enhances net sodium and water secretion into the intestinal lumen $(29,30)$. Toxin-mediated guanylyl cyclase activity produces a form of secretory diarrhea commonly termed "traveler's diarrhea." In the present study, the stimulation of particulate guanylyl cyclase by STa resulted in a marked increase in cGMP content in the lumen but no increase in cGMP in the interstitial fluid. This response was accompanied by secretion and was not inhibited by L-NAME. In contrast, the intravenous L-arginine-induced increase in cGMP (similar to 
that of ANG II via the $\mathrm{AT}_{2}$ receptor) in both the interstitial fluid and in the lumen was blocked completely with LNAME, suggesting that L-arginine stimulates soluble guanylyl cyclase, resulting in an absorptive instead of a secretory response. Furthermore, the increase in fluid absorption engendered by L-arginine was blocked completely by the soluble guanylyl cyclase inhibitor ODQ, confirming our hypothesis that the increase in absorption is mediated by the ability of nitric oxide to stimulate soluble guanylyl cyclase and to release cyclic GMP.

Because cGMP in the interstitial space (the serosal side) was associated with a difference in fluid transport (absorptive), we sought to clarify a possible role for serosal cGMP as a mediator of fluid transport. Hamet et al. (31) have demonstrated that ${ }^{3} \mathrm{H}-\mathrm{cGMP}$ added to the serosal environment is not taken up by smooth muscle or endothelial cells. Our data with cGMP and 8-Br-cGMP suggested that serosal cGMP may play a role as an extracellular (paracrine or autocrine) mediator of the fluid absorptive response because selective reduction of interstitial fluid cGMP with phosphodiesterase, which does not traverse the cell membrane due to its high molecular weight, completely inhibited the absorptive response to intravenous L-arginine. While cGMP fails to be taken up by intestinal epithelial cells, it is possible that it may be taken up into enteric nerves or endocrine cells, which could serve as intermediates in the transport effects of ANG II. Cyclic GMP has been demonstrated to be released into the serosal environment in the kidney, and it is possible that the extruded cGMP could mediate sodium and water transport across the renal tubule epithelium $(32,33)$. The results of this study strongly support the hypothesis that cGMP may function as a paracrine or autocrine substance, as well as an intracellular mediator, and that extracellular cGMP is required for nitric oxide stimulation of absorption. Further study in isolated transporting epithelial cell preparations will be required to clarify these relationships.

This study introduces the novel concept of cyclic nucleotide compartmentalization and autocrine/paracrine action on biological processes. Further exploration of the cell types involved in these processes will likely require the study of functional epithelial cell monolayers, such as those we are currently pursuing.

1. Levens, N.R. 1985. Control of intestinal absorption by the reninangiotensin system. Am. J. Physiol. 249:G3-G15.

2. Bolton, J.E., Munday, K.A., Parsons, B.J., and York, B.G. 1975. Effects of angiotensin II on fluid transport, transmural potential difference and blood flow by rat jejunum in vivo. J. Physiol. Lond. 253:411-428.

3. Levens, N.R., Peach, M.J., and Carey, R.M. 1981. Interactions between angiotensin peptides and the sympathetic neurons system mediating intestinal sodium and water absorption in the rat. J. Clin. Invest. 67:1197-1207.

4. Cox, H.M., Cuthbert, A.W., and Munday, K.A. 1987. The effect of angiotensin II upon electrogenic ion transport in rat intestinal epithelia. Br. J. Pharmacol. 90:393-401.

5. Harris, P.J. 1979. Stimulation of proximal tubular sodium reabsorption by ile5 angiotensin II in the rat kidney. Eur. J. Physiol. 381:83-85.

6. Harris P.J., and Young, J.A. 1977. Dose-dependent stimulation and inhibition of proximal tubular sodium reabsorption by angiotensin II in the rat kidney. Eur. J. Physiol. 367:295-297.

7. Jin, X.H., Wang, Z.Q., Siragy, H.M., Guerrant, R.L., and Carey, R.M. 1998.
Regulation of jejunal sodium and water absorption by angiotensin subtype receptors in the rat: role of cyclic nucleotides and prostaglandin $\mathrm{E}_{2}$. Am.J. Physiol. 275:R515-R523.

8. Hughes, J.M., Murad, F., Chang, B., and Guerrant, R.L. 1978. Role of cyclic GMP in the action of heat-stable enterotoxin of Escherichia coli. Nature. 271:755-756.

9. Joe, N.S., Kim, H.D., Forte, L.R., and Clarke, L.L. 1997. Uroguanylin regulation of anion secretion in mouse intestine. FASEB J. 11:A297. (Abstr.)

10. Younoszai, M.K., and Schedl, H.P. 1970. Vitamin D deficiency and neutral amino acid absorption in the rat intestine. Proc. Soc. Exp. Biol. Med. 134:562-565.

11. Green, R.S., MacDermid, R.G., Scheig, R.L., and Hajjar, J.-J. 1981. Effect of ethanol on amino acid absorption across in vivo rat intestine. Am. J. Physiol. 241:G176-G181.

12. Richterich, R. 1965. Inulin (Fructose). In Klinische Chemie, Theorie und Praxis. Akademische vertagsgellschraft. Frankfurt, Germany. 373-374.

13. Siragy, H.M., and Carey, R.M. 1996. The subtype-2 $\left(\mathrm{AT}_{2}\right)$ angiotensin receptor regulates renal guanosine $3^{\prime}, 5^{\prime}$-monophosphate and $\mathrm{AT}_{1}$ receptor-mediated prostaglandin $\mathrm{E}_{2}$ production in conscious rats. J. Clin. Invest. 97:1978-1982.

14. Siragy, H.M., Howell, N.L., Ragsdale, N.V., and Carey, R.M. 1995. Renal interstitial fluid angiotensin modulation by anesthesia, epinephrine, sodium depletion, and renin inhibition. Hypertension. 25:1021-1024

15. Macari, D., Bottani, S., Whitbread, S., deGasparo, M., and Levens, N.R. 1993. Renal actions of the selective angiotensin $\mathrm{AT}_{2}$ receptor ligands CGP 42112 and PD 123319 in the sodium-depleted rat. Eur. J. Pharmacol. 249:85-93.

16. Olson, I.J., Knych, E.T., Herzog, T.C., and Drewett, J.G. 1997. Selective guanyl cyclase inhibitor reverses nitric oxide-induced vasorelaxation. Hypertension. 29:254-261.

17. Li, P.-L., Jin, M.-W., and Campbell, W.B. 1998. Effect of selective inhibition of soluble guanylyl cyclase on the $\mathrm{K}$-Ca channel activity in coronary artery smooth muscle. Hypertension. 31:303-308.

18. Stryer, L. 1991. Visual excitation and recovery. J. Biol. Chem. 266:10711-10714.

19. Schirgi-Degen, A., and Beubler, E. 1995. Significance of nitric oxide in the stimulation of intestinal fluid absorption in the rat intestine in vivo. $\mathrm{Br}$. J. Pharmacol. 114:13-18.

20. Schirgi-Degen, A., and Beubler, E. 1996. Involvement of K-1 channel modulation in the proabsorptive effect of nitric oxide in the rat jejunum in vivo. Eur. J. Pharmacol. 316:257-262.

21. Mourad, F.H., et al. 1996. L-arginine, nitric oxide, and intestinal secretion: studies in rat jejunum in vivo. Gut. 39:539-544.

22. Beubler, E., and Schirgi-Degen, A. 1997. Nitric oxide counteracts 5hydroytryptamine- and cholear toxin-induced fluid secretion and enhances the effect of oral rehydration solution. Eur. J. Pharmacol. 326:223-228.

23. Cahill, P.A., Redmond, E.M., Foster, C., and Sitzmann, J.V. 1995. Nitric oxide regulates angiotensin II receptors in vascular smooth muscle cells. Eur. J. Pharmacol. 288:219-229.

24. Hennington, B.S., Zhang, H., Miller, M.T., Granger, J.P., and Reckelhoff, J.F. 1998. Angiotensin II stimulates synthesis of endothelial nitric oxide synthase. Hypertension. 31:283-288.

25. Komalavilas, P., and Lincoln, T.M. 1996. Phosphorylation of inositol 1,4,5trisphosphate receptor. Cyclic GMP-dependent protein kinase mediates cAMP and cGMP dependent phosphorylation in the intact rat aorta. J. Biol. Chem. 271:21933-21938.

26. Wiemer G., Scholkens, B.A., Wagner, A., Heitsch, H., and Linz, W. 1993. The possible role of angiotensin II subtype $\mathrm{AT}_{2}$ receptors in endothelial cells and isolated ischemic rat hearts. J. Hypertension. 11(Suppl. 5):234-235.

27. Gohlke, P., Pees, C., and Unger, T. 1998. AT 2 receptor stimulation increases aortic cyclic GMP in SHRSP by a kinin-dependent mechanism. Hypertension. 31:349-355.

28. Siragy, H.M., and Carey, R.M. 1997. The subtype $2\left(\mathrm{AT}_{2}\right)$ angiotensin receptor mediates renal production of nitric oxide in conscious rats. J. Clin. Invest. 100:264-269.

29. Hamra, F.K., Eber, S.L., Chin, D.T., Currie, M.G., and Forte, L.R. 1997. Regulation of intestinal uroguanylin/guanylin receptor-mediated responses by mucosal acidity. Proc. Natl. Acad. Sci. USA. 94:2705-2710.

30. Hamra, F.K., et al. 1996. Opossum colonic mucosa contains uroguanylin and guanylin peptides. Am. J. Physiol. 270:G708-G716.

31. Hamet, P., Pang, S.C., and Tremblay, J. 1989. Atrial natriuretic factorinduced egression of cyclic guanosine $3^{\prime}, 5^{\prime}$-monophosphate in cultured vascular smooth muscle and endothelial cells. J. Biol. Chem. 264:12364-12369.

32. Chevalier, R.L., et al. 1992. Localization of cGMP following infusion of ANP or nitroprusside in the maturing rat. Am. J. Physiol. 262:F417-F424.

33. Chevalier, R.L., Fang, G.D., and Garmey, M. 1996. Extracellular cGMP inhibits transepithelial sodium transport by LLC-PK, renal tubular cells. Am. J. Physiol. 270:F283-F288. 